\title{
Influence of seed treatment and abiotic factors on damage to $B t$ and non- $B t$ cotton genotypes by the serpentine leaf miner Liriomyza trifolii (Diptera: Agromyzidae)
}

\author{
M.K. Dhillon ${ }^{1}$ and H.C. Sharma ${ }^{2 *}$ \\ ${ }^{1}$ Division of Entomology, Indian Agricultural Research Institute (IARI), \\ New Delhi 110 012, India: ${ }^{2}$ International Crops Research Institute \\ for the Semi-Arid Tropics (ICRISAT), Patancheru 502 324, \\ Andhra Pradesh, India
}

(Accepted 8 July 2010)

\begin{abstract}
In recent years, the serpentine leaf miner Liriomyza trifolii (Burgess) has become a major pest of cotton (Gossypium spp.) in India, with high levels of incidence observed at the seedling stage, particularly in transgenic Bt cotton. We monitored the severity of infestation and damage by L. trifolii to transgenic and non-transgenic genotypes of Gossypium arboreum L. and G. hirsutum L. between 2002 and 2007. Overall, significantly lower L. trifolii damage occurred in G. arboreum varieties than in G. hirsutum varieties and hybrids. Among the G. hirsutum genotypes, damage was significantly lower in varieties than in hybrids. However, no significant differences in damage were observed between $B t$ and non-Bt cotton hybrids. Abiotic factors had a major influence on the severity of damage; there was a significant and negative association of L. trifolii damage with open pan evaporation (E), maximum temperature, solar radiation and sunshine, and a significant and positive association with relative humidity and rainfall (RF). Multiple stepwise regression analysis indicated that $99 \%$ of the variation in L. trifolii damage was accounted for by RF, open pan $\mathrm{E}$ and relative humidity.
\end{abstract}

Key words: serpentine leaf miner, Liriomyza trifolii, transgenic Bt cotton, Gossypium hirsutum, Gossypium arboreum, abiotic factors, India

\section{Introduction}

The serpentine leaf miner Liriomyza trifolii (Burgess) (Diptera: Agromyzidae) is a polyphagous pest that feeds on over 400 plant species, including cotton, cucurbits, solanaceous vegetables and brassicas (Parrella, 1987; Srinivasan et al., 1995; Singh et al., 1996; Murphy and La Salle, 1999; Lei et al., 2007). Feeding and oviposition punctures made by females result in stippling of foliage, especially at the leaf tip and along the leaf margins. Larvae feed on the leaf mesophyll along the leaf veins, forming zigzag mines that become

*E-mail: h.sharma@cgiar.org noticeable a few days after oviposition and gradually widen and lengthen as the maggot matures. Both stippling and mining hamper photosynthesis, and severe infestation results in premature defoliation or complete desiccation of leaves (Parrella et al., 1985). Wounding of the foliage also allows the entry of pathogenic bacteria and fungi into the plant (Broadbent and Matteoni, 1990).

Liriomyza trifolii is believed to be of Neotropical origin; until the 1970s, its damage occurred only in the Caribbean and in southern and eastern USA (Parrella, 1987). In India, L. trifolii damage was first reported from castor (Ricinus communis L.) in 1992 (Laxminarayana et al., 1992) and was subsequently observed on cotton, cowpea, sunflower, cucumber, 
celery, chrysanthemum, chilli and rapeseed-mustard in 1993 (Singh et al., 1996). Recently, L. trifolii has become a major pest of cotton in many countries, including India (Srinivasan et al., 1995; Jeyakumar and Uthamasamy, 1996), Israel (Yathom, 1989), USA (Arizona; Palumbo, 1992) and Turkey (Gencsoylu, 2003). The pest causes severe damage during the seedling stage of the crop. The economic threshold of L. trifolii in beans (Cikman and Comlekcioglu, 2006) has been reported, but there is no information on economic thresholds for the pest on cotton. Such information is essential for timely and targeted pest management action.

Transgenic $B t$ cotton hybrids have been deregulated and adopted on a large scale by farmers in India (Mohan and Manjunath, 2002; James, 2008). Seed treatment with imidacloprid is a common practice for the management of sucking pests during the vegetative stage (up to 45 days after seedling emergence (DAE)). At the initiation of fruiting bodies, economically important insect pests such as whiteflies, leafhoppers, aphids and bollworms are managed predominantly with insecticides. Since the introduction of transgenic $B t$ cotton hybrids in the country, the serpentine leaf miner L. trifolii (at seedling stage) and the mealy bugs Phenacoccus solenopsis (Tinsley) and Maconellicoccus hirsutus (Green) (throughout the crop season) are becoming major pests of cotton (Karihaloo and Kumar, 2009; Nagrare et al., 2009).

We studied L. trifolii damage to different cotton genotypes, both non- $B t$ and $B t$, with and without imidacloprid seed treatment. We also assessed the influence of abiotic factors, namely temperature, relative humidity, rainfall (RF), evaporation (E), solar radiation (SR) and sunshine (S), on the incidence of L. trifolii.

\section{Materials and methods}

Gossypium arboreum varieties, G. hirsutum varieties and $G$. hirsutum hybrids (Bt hybrids expressing $c r y 1 A c$ and $c r y 1 A c+c r y 2 A b$ genes and nontransgenic ones) (Table 1) were grown under field conditions on deep black vertisols during the 20022007 crop growing seasons (July-December) at the International Crops Research Institute for the SemiArid Tropics (ICRISAT) in Patancheru, Andhra Pradesh, India. Seeds of the test cultivars (Aravinda, MDL 2450, L 604, LK 861, Mech 12, Mech 162, Mech 184, RCH 2, NCS 207 and MRC 7201 BGII) were sown in four-row plots of 4-m length on ridges with $75-\mathrm{cm}$ inter-ridge spacing and $50-\mathrm{cm}$ inter-plant spacing, accommodating a total of 36 plants per plot. The experiment was planted in three replications in a split-plot design. Seed treatment was the main treatment, and genotype was the sub-treatment. Seeds of one set of genotypes were treated with
Table 1. Cotton genotypes evaluated for Liriomyza trifolii damage during the 2002-2007 cropping seasons

\begin{tabular}{lc}
\hline Genotypes & Cropping seasons (years) \\
\hline Gossypium arboreum & varieties \\
Aravinda & 2002, 2003, 2004 \\
MDL 2450 & 2002, 2003, 2004, 2007 \\
Gossypium hirsutum & varieties \\
LK 861 & 2002, 2003, 2004 \\
L 604 & 2002, 2003, 2004, 2007 \\
Gossypium hirsutum & non-Bt hybrids \\
Mech 162 & $2002,2003,2004,2005,2006,2007$ \\
Mech 12 & $2003,2004,2005,2006$ \\
Mech 184 & $2003,2004,2005,2006,2007$ \\
RCH 2 & $2005,2006,2007$ \\
NCS 207 & 2006,2007 \\
MRC 7201 BGII & 2006,2007 \\
Gossypium hirsutum Bt hybrids \\
Mech 162 & $2002,2003,2004,2005,2006,2007$ \\
Mech 12 & $2003,2004,2005,2006$ \\
Mech 184 & $2003,2004,2005,2006,2007$ \\
RCH 2 & $2005,2006,2007$ \\
NCS 207 & 2006,2007 \\
MRC 7201 BGII & 2006,2007 \\
\hline
\end{tabular}

imidacloprid at $2 \mathrm{~g} / \mathrm{kg}$ seed, while another set was left untreated. The crop was raised under rain-fed conditions following normal agronomic practices, including the application of a basal fertilizer (N:P:K = 100:40:60 kg/ha).

The total number of leaves and the number of leaves mined by L. trifolii at 30 DAE were counted on five randomly tagged plants in the middle two rows of each plot, and the data were used to calculate the percentage of leaves mined.

To determine whether there was any $B t$ toxin uptake by the leaf miners from $B t$ cotton, we collected L. trifolii pupae from transgenic $B t$ and non-transgenic cotton hybrids in eppendorf tubes, crushed them in phosphate-buffered saline buffer at the ratio of 1:10 (insect sample: buffer) and used a semi-quantitative ELISA (Agdia ${ }^{\circledR}$, Elkhart, Indiana, USA) to detect $B t$ toxins present in the pupae (Sharma et al., 2008).

Data on maximum (MaxT) and minimum (MinT) temperatures $\left({ }^{\circ} \mathrm{C}\right)$, morning (RHM) and evening (RHE) relative humidity (\%), rainfall (RF) $(\mathrm{mm})$, sunshine $(\mathrm{S})(\mathrm{h})$, open pan evaporation $(\mathrm{E})$ $(\mathrm{mm})$, wind velocity $(\mathrm{WV})$ and solar radiation (SR) $\left(\mathrm{mJ} / \mathrm{m}^{2}\right)$ were obtained from the ICRISAT meteorological observatory. Means for each weather parameter (from crop germination to $30 \mathrm{DAE}$ ) were used for analysing the correlation of abiotic factors with $L$. trifolii incidence across seasons.

\section{Statistical analysis}

The data were subjected to ANOVA using factorial analysis, with transgenic $B t /$ non-transgenic and 
seed treatment as the main treatments and cotton cultivars as the sub-treatments (GenStat, 2008). The significance of differences between the treatments and their interactions were determined using an F-test. The interaction effects of genotypes (different varieties/hybrids of a specific cotton species) $\times$ treatments (seed treatment/untreated) $\times$ seasons and cotton types (G. arboreum varieties, G. hirsutum varieties, G. hirsutum Bt hybrids and G. hirsutum non-Bt hybrids) were also computed. Association between $L$. trifolii incidence and abiotic factors, and the influence of abiotic factors on L. trifolii incidence were analysed using Spearman's correlation analysis and multiple linear and stepwise regressions (Dhillon et al., 2005).

\section{Results}

\section{Effect of seed treatment and genotype}

There was a significant influence of cotton types $\left(F_{3,134}=168.83 ; P<0.001\right)$ and seed treatment $\left(F_{1,134}=9.32 ; P=0.003\right)$ on the severity of damage by $L$. trifolii, which varied significantly across years $\left(F_{5,134}=78.59 ; P<0.001\right)$. Leaf miner damage to different cotton genotypes, both with and without seed treatment, increased from 2002 to 2007, except during 2006 (Fig. 1). However, cotton type $\times$ treatment $\times$ season interaction effects were non-significant $\left(F_{9,134}=0.26 ; P=0.98\right)$.

Liriomyza trifolii incidence in $G$. arboreum varieties varied from 12.8 to $45.1 \%$ and was significantly greater in plots with insecticidetreated seed than in untreated control plots (Table 2), probably because of the abundance of healthy leaves in treated plots and the ineffectiveness of imidacloprid in the control of L. trifolii. Damage was significantly lower in G. arboreum than in G. hirsutum varieties (Table 2), and seed treatment with imidacloprid was ineffective in controlling leaf miner damage to $G$. hirsutum varieties and hybrids (Tables 2 and 3).

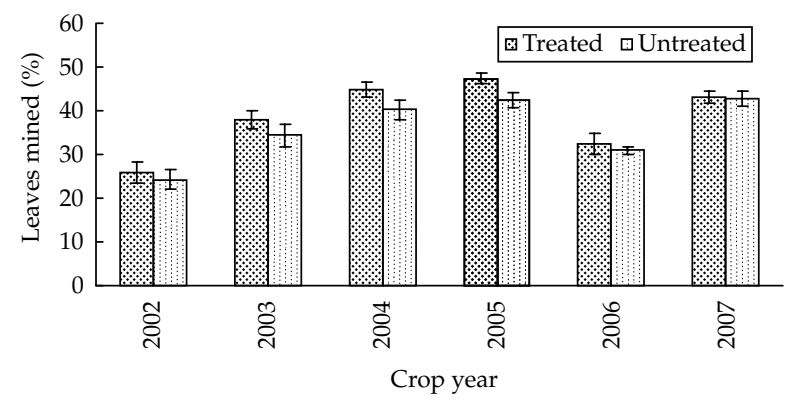

Fig. 1. Liriomyza trifolii damage to cotton under seedtreated and untreated conditions during the 2002-2007 cropping seasons
Liriomyza trifolii incidence in G. hirsutum Bt and non-transgenic cotton hybrids varied from 32.6 to $47.9 \%$ and from 31.2 to $52.2 \%$, respectively, across cropping seasons (Table 3). Among the cotton hybrids, L. trifolii incidence was significantly lower in MRC 7201 BGII and NCS 207 than in the other test hybrids (Table 3). There were significant differences in damage among the genotypes $\left(F_{5,174}=13.74 ; \quad P<0.001\right)$ and across seasons $\left(F_{5,174}=67.91 ; P<0.001\right)$. However, no significant differences were noted among the seed-treated genotypes $\left(F_{3,174}=2.43 ; P=0.07\right)$. Genotype $\times$ treatment $\times$ season interaction effects for leaf miner incidence were non-significant $\left(F_{33,174}=1.18\right.$; $P=0.24)$.

The L. trifolii pupae collected from the leaves of $B t$ cotton hybrids contained up to $1.35 \mathrm{ppb} B t$ toxin, indicating uptake of the toxin by the leaf miner larvae; however, $B t$ uptake had no effect on damage by $L$. trifolii larvae to the $B t$ and non-Bt cotton hybrids.

\section{Influence of abiotic factors}

Open pan evaporation $\left(r=-0.53^{* *}\right)$, maximum temperature $\left(r=-0.50^{* *}\right)$, solar radiation $\left(r=-0.50^{* *}\right)$ and sunshine $\left(r=-0.49^{* *}\right)$ had a negative influence on $L$. trifolii incidence, while relative humidity $\left(r=0.46^{* *}\right)$ and rainfall $\left(r=0.35^{*}\right)$ had a positive influence $(* * * *=P 0.05$, and 0.01 , respectively). Multiple linear regression indicated that abiotic factors, namely sunshine, open pan evaporation, maximum and minimum temperatures, morning and evening relative humidity, rainfall, solar radiation and wind velocity explained $73 \%$ of the variation in L. trifolii damage (leaf miner damage $(\%)=43377+8.0 \mathrm{~S}+244.0 \mathrm{E}+103.9$ MaxT+23.0 MinT - 418.0 RHM + 24.0 RHE + 36.2 $\left.\mathrm{RF}-893.0 \mathrm{SR}-65.0 \mathrm{WV} \quad\left(R^{2}=0.73\right)\right)$. However, stepwise regression (leaf miner damage $(\%)=$ $\left.74.74-1.36 \mathrm{RF}-7.77 \mathrm{E}+0.28 \mathrm{RHE}\left(R^{2}=0.99\right)\right)$ suggested that $99 \%$ of the variation in L. trifolii damage was associated with rainfall, open pan evaporation and relative humidity.

\section{Discussion}

Liriomyza trifolii damages cotton during the early stages of crop growth (Srinivasan et al., 1995; Jeyakumar and Uthamasamy, 1996), preferring younger leaves for feeding and oviposition (Lei et al., 2009). The production of $B t$ proteins in the transgenic hybrids (expressing cry $1 A c$ and $c r y 1 A c+c r y 2 A b$ genes) occurs mostly during the vegetative stage of the crop, and predominantly in leaves (Kranthi et al., 2005). Although the L. trifolii pupae collected from the leaves of $B t$ cotton hybrids imbibed a trace amount of $B t$ toxin, there were no 
Table 2. Efficacy of imidacloprid seed treatment on reduction of serpentine leaf miner Liriomyza trifolii damage to Gossypium arboreum and G. hirsutum varieties

\begin{tabular}{|c|c|c|c|c|c|c|c|c|}
\hline \multirow[b]{3}{*}{ Genotypes } & \multicolumn{8}{|c|}{ Leaves mined (\%) during different crop years ${ }^{1}$} \\
\hline & \multicolumn{2}{|c|}{2002} & \multicolumn{2}{|c|}{2003} & \multicolumn{2}{|c|}{2004} & \multicolumn{2}{|c|}{2007} \\
\hline & Treated & Untreated & Treated & Untreated & Treated & Untreated & Treated & Untreated \\
\hline \multicolumn{9}{|l|}{ G. arboreum } \\
\hline Aravinda & $30.1 \pm 5.0$ & $14.8 \pm 1.5$ & $29.3 \pm 4.9$ & $17.6 \pm 1.6$ & $28.5 \pm 4.9$ & $20.3 \pm 2.2$ & $-^{2}$ & $-^{2}$ \\
\hline MDL 2450 & $12.8 \pm 1.9$ & $12.3 \pm 3.7$ & $21.2 \pm 2.6$ & $14.8 \pm 1.8$ & $29.6 \pm 5.9$ & $17.2 \pm 1.7$ & $23.3 \pm 0.8$ & $17.1 \pm 2.4$ \\
\hline \multicolumn{9}{|l|}{ G. hirsutum } \\
\hline LK 861 & $37.0 \pm 0.9$ & $37.5 \pm 3.7$ & $40.5 \pm 2.0$ & $41.3 \pm 2.2$ & 44. & 0.8 & $-^{2}$ & $-^{2}$ \\
\hline L 604 & $25.2 \pm 3.6$ & $24.9 \pm 2.3$ & $34.1 \pm 1.8$ & $29.4 \pm 1.1$ & $43.0 \pm 1.6$ & $34.0 \pm 1.1$ & $40.2 \pm 2.1$ & $41.7 \pm 1.5$ \\
\hline
\end{tabular}

${ }^{1}$ Values presented are means of three replications \pm standard error; ${ }^{2}-$, data not available.

significant differences in leaf damage by the leaf miner larvae in the $B t$ and non- $B t$ cotton hybrids.

Liriomyza trifolii damage was significantly lower in $G$. arboreum cotton varieties than in the G. hirsutum varieties and hybrids across treatments and cropping seasons. No significant differences, however, were observed between $B t$ and non- $B t$ cotton hybrids.

Another plausible reason for the increased severity of L. trifolii damage to Bt cotton over the previously grown conventional cotton might be that broad spectrum insecticides for the control of lepidopteran pests are not as frequently used on $B t$ cotton as they are on conventional cotton. In addition, inherent differences in susceptibility to leaf damage among the different cotton genotypes, as previously observed by Sharma and Pampapathy (2006), may play a role.

Seed treatment with imidacloprid was found to be ineffective for the control of leaf miner damage, indicating the need to identify alternative strategies for the management of this and similar sucking pests.

Although L. trifolii pupae collected from the leaves of $B t$ cotton hybrids had ingested trace amounts of $B t$ toxin, no significant differences in leaf damage by $L$. trifolii to $B t$ and non- $B t$ cotton hybrids were recorded in our study. Lei et al. (2009), however, observed a reduction in L. trifolii damage on $B t$ cotton leaves. In addition, $B t$-sprayed chickpea and bean crops showed lower damage by L. cicerina (Rondani) (Cikman et al., 2008) and L. trifolii (Cikman and Comlekcioglu, 2006), respectively.

Abiotic factors had a large and significant influence on L. trifolii damage, similar to previous studies. For instance, abiotic factors account for over $90 \%$ of L. trifolii incidence in castor (Singh et al., 1996). The present study suggested that $99 \%$ of the variation in $L$. trifolii damage was due to rainfall, open pan evaporation and relative humidity. Evidently, the serpentine leaf miner is highly sensitive to changes in environmental conditions. As such, climate change and widespread cultivation of leaf miner susceptible cotton genotypes, including transgenic $B t$ cottons, might lead to L. trifolii becoming a major pest in the future. There is an urgent need to devise better control strategies for the pest, including alternative seed treatments and leaf miner-resistant genotypes.

Table 3. Effect of imidacloprid seed treatment on damage by the serpentine leaf miner Liriomyza trifolii to Gossypium hirsutum Bt and non-Bt cotton hybrids

\begin{tabular}{lcccc}
\hline & \multicolumn{3}{c}{ Leaves mined (\%) in different treatments } \\
\cline { 2 - 5 } Genotypes $^{1}$ & $B t+\mathrm{T}$ & $B t+\mathrm{UT}$ & Non- $B t+\mathrm{T}$ & Non-Bt + UT \\
\hline Mech 12 (4) & $44.5 \pm 2.5$ & $38.9 \pm 2.8$ & $52.2 \pm 5.5$ & $44.3 \pm 1.5$ \\
Mech 162 (6) & $40.8 \pm 2.9$ & $41.0 \pm 2.3$ & $42.3 \pm 2.5$ & $41.6 \pm 2.6$ \\
Mech 184 (5) & $47.9 \pm 1.7$ & $43.8 \pm 2.0$ & $44.8 \pm 2.1$ & $44.1 \pm 2.1$ \\
RCH 2 (3) & $42.0 \pm 3.9$ & $41.6 \pm 3.6$ & $41.3 \pm 3.1$ & $36.5 \pm 2.7$ \\
NCS 207 (2) & $32.6 \pm 4.0$ & $35.2 \pm 4.6$ & $36.2 \pm 5.2$ & $31.2 \pm 2.4$ \\
MRC 7201 BGII (2) & $33.6 \pm 2.8$ & $36.2 \pm 3.3$ & $34.0 \pm 3.2$ & $35.6 \pm 3.5$ \\
\hline
\end{tabular}

T, seed treated with imidacloprid; UT, no seed treatment; ${ }^{1}$ figures in parentheses are numbers of years tested; ${ }^{2}$ values presented are means across seasons \pm standard error. 


\section{Acknowledgements}

We are grateful to Dr David Henshaw for his support with identifying L. trifolii. We acknowledge the funding received from the Swiss Agency for Development and Cooperation, Berne; the Departments of Biotechnology and Science and Technology, New Delhi; and the IndoSwiss Collaboration on Biotechnology.

\section{References}

Broadbent A. B. and Matteoni J. A. (1990) Acquisition and transfer of Pseudomonas chichori by Liriomyza trifolii (Diptera: Agromyzidae). Proceedings of the Entomological Society, Ontario 121, 79-84.

Cikman E. and Comlekcioglu N. (2006) Effects of Bacillus thuringiensis on larval serpentine leafminers Liriomyza trifolii (Burgess) (Diptera: Agromyzidae) in bean. Pakistan Journal of Biological Sciences 9, 2082-2086.

Cikman E., Kaplan M. and Coskun Y. (2008) The effects of Bacillus thuringiensis on larval serpentine leaf miners Liriomyza cicerina (Rondani, 1875) (Diptera: Agromyzidae) in chickpea. Journal of Applied Sciences Research 4, 1191-1198.

Dhillon M. K., Sharma H. C., Singh R. and Naresh J. S. (2005) Mechanisms of resistance to shoot fly, Atherigona soccata in sorghum. Euphytica 144, 301-312.

Gencsoylu I. (2003) A new pest, Liriomyza trifolii, on cotton in the Buyuk Menderes Valley, Turkey. Phytoparasitica 31, 330-332.

GenStat (2008) Introduction to GenStat for Windows ${ }^{\circledR}$. Genstat, 10th edn. Lawes Agricultural Trust, Rothamsted Experimental Station, Harpenden.

James C. (2008) Global Status of Commercialized Biotech/GM Crops: 2008. ISAAA Brief No. 38. International Service for the Acquisition of Agri-Biotech Applications, Ithaca, New York.

Jeyakumar P. and Uthamasamy S. (1996) Ovipositional preference and damage potential of Liriomyza trifolii (Burgess) on cotton. Journal of Entomological Research 20, 157-161.

Karihaloo J. L. and Kumar P. A. (2009) Bt Cotton in India - A Status Report. 2nd edn. 56 pp. Asia-Pacific Consortium on Agricultural Biotechnology (APCoAB), New Delhi.

Kranthi K. R., Naidu K., Dhawad C. S., Tatwawadi A., Mate K., Patil E., Bharose A. A., Behere G. T., Wadaskar R. M. and Kranthi S. (2005) Temporal and intra-plant variability of $c r y 1 A c$ expression in $B t$-cotton and its influence on the survival of the cotton bollworm, Helicoverpa armigera (Hubner) (Lepidoptera: Noctuidae). Current Science 89, 291-298.

Laxminarayana M., Basappa H. and Singh V. (1992) Report on the incidence of hitherto unknown leaf miner, Liriomyza trifolii Burgess (Dip.: Agromy.) on castor. Journal of Oilseeds Research 9, 175-176.

Lei Z., Liu T. X. and Greenberg S. M. (2009) Feeding, oviposition and survival of Liriomyza trifolii (Diptera: Agromyzidae) on Bt and non-Bt cottons. Bulletin of Entomological Research 99, 253-261.

Lei Z. R., Zhu C. J. and Zhang C. Q. (2007) Risk analysis of alien invasive Liriomyza trifolii (Burgess) in China. Plant Protection 33, 37-40.

Mohan K. S. and Manjunath T. M. (2002) Bt cotton India's first transgenic crop. Journal of Plant Biology 29, 225-236.

Murphy S. T. and La Salle J. (1999) Balancing biological control strategies in the IPM of new world invasive Liriomyza leafminers in field vegetable crops. BioControl 20, 91-104.

Nagrare V. S., Kranthi S., Biradar V. K., Zade N. N., Sangode V., Kakde G., Shukla R. M., Shivare D., Khadi B. M. and Kranthi K. R. (2009) Widespread infestation of the exotic mealybug species, Phenacoccus solenopsis (Tinsley) (Hemiptera: Pseudococcidae), on cotton in India. Bulletin of Entomological Research 99, 537-541.

Palumbo J. C. (1992) Identification and occurrence of Liriomyza species associated with cotton in Arizona. Southwestern Entomologist 17, 69-70.

Parrella M. P. (1987) Biology of Liriomyza. Annual Review of Entomology 32, 201-224.

Parrella M. P., Jones V. P., Youngman R. R. and Lebeck L. M. (1985) Effect of leaf mining and leaf stippling of Liriomyza spp. on photosynthetic rates of chrysanthemum. Annals of the Entomological Society of America 78, 90-93.

Sharma H. C., Dhillon M. K. and Arora R. (2008) Effects of Bacillus thuringiensis $\delta$-endotoxin-fed Helicoverpa armigera on the survival and development of the parasitoid Campoletis chlorideae. Entomologia Experimentalis et Applicata 126, 1-8.

Sharma H. C. and Pampapathy G. (2006) Influence of transgenic cotton on the relative abundance and damage by target and non-target insect pests under different protection regimes in India. Crop Protection $25,800-813$.

Singh H., Malik V. S. and Kumar M. (1996) Role of abiotic factors in seasonal incidence and biology of American serpentine leaf miner, Liriomyza trifolii (Burgess) (Diptera: Agromyzidae) on castor. Indian Journal of Ecology 23, 34-38.

Srinivasan K., Viraktamath C. A., Gupta M. and Tewari G. C. (1995) Geographical distribution, host range and parasitoids of serpentine leaf miner, Liriomyza trifolii (Burgess) in South India. Pest Management in Horticulture Ecosystems 1, 93-100.

Yathom S. (1989) New pest and disease records, Liriomyza trifolii on cotton seedlings in Israel. Phytoparasitica 17, 327-328. 